\title{
CHANGES IN LARYNX AND TRACHEA IN POSTINTUBATED PATIENTS
}

\author{
B. Maruthi Rao ${ }^{1}$, S. Ramesh ${ }^{2}$ \\ ${ }^{1}$ Tutor, Department of ENT, RIMS, Srikakulam. \\ ${ }^{2}$ Assistant Professor, Department of ENT, RIMS, Srikakulam.
}

\begin{abstract}
Present critical care units have a significant number of patients who require intubation for prolonged periods of time. With the advent of high volume low-pressure tubes, it is common for the patients to be ventilated through the endotracheal tube for up to 3 weeks in the ICU. The sequelae of intubation depend on multiple factors and can also at times be a major source of morbidity to the patient during recovery. Laryngeal complications after prolonged intubations have varied incidence rates in the literature. Hoarseness of voice, cough, dysphagia, aspiration and stridor can develop after extubation. Common injuries following long-term intubation can manifest in the form of edema, ulceration, granulomas, arytenoid dislocations, adhesions, subglottic stenosis and vocal fold immobility, etc. This study conducted in our ENT Department is based on cases with changes in larynx and trachea following prolonged intubation in Intensive Care Units of Government General Hospital, attached to Rangaraya Medical College, Kakinada, during a period of about two years (September 2011 to August 2013). In our study, 20 patients (66.67\%) had lesions only in larynx and 10 patients (33.33\%) had lesions in both larynx and trachea. Laryngotracheal sequelae in long-term intubation which showed the increased incidence of complications in patients with more than 10-14 days intubation.
\end{abstract}

\section{KEYWORDS}

Intubation, Laryngeal, tracheal, granulomas, subglottic stenosis.

HOW TO CITE THIS ARTICLE: Rao BM, Ramesh S. “Changes in larynx and trachea in postintubated patients.” Journal of Evolution of Medical and Dental Sciences 2015; Vol. 4, Issue 103, December 24; Page: 16838-16843, DOI: 10.14260/jemds/2015/2529

\section{INTRODUCTION}

At present critical care units have a significant number of patients who require intubation for prolonged periods of time. While the indications for intubation are varied, it is commonly used for ventilatory assistance, airway protection and relief of respiratory embarrassment and to aid in tracheobronchial toilet.

Previously translaryngeal endotracheal intubation is used only for general anesthesia for surgical procedures, which lasted only a few hours. A remarkable advancement in the $20^{\text {th }}$ century is the establishment of well equipped critical care units. Further, there has been a significant rise in the number of patients requiring intubation.

With the advent of high volume low-pressure tubes, it is common for the patients to be ventilated through the endotracheal tube for up to 3 weeks in the ICU. The sequelae of intubation depend on multiple factors and can also at times be a major source of morbidity to the patient during recovery. Laryngeal complications after prolonged intubations have varied incidence rates in the literature.

Hoarseness of voice, cough, dysphagia, aspiration and stridor can develop after extubation. A significant number of such patients present to ENT Department. Laryngeal evaluation of such patients becomes necessary to assess the nature of airway injury like laryngeal and tracheal sequelae following prolonged intubation. Common injuries following long-term intubation can manifest in the form of edema, ulceration, granulomas, arytenoid dislocations, adhesions, subglottic stenosis and vocal fold immobility, etc.

\section{Pathophysiology of Laryngeal Changes After Endotracheal Intubation \\ Lindholm. ${ }^{1}$ in his wide-ranging study established that the size}

Financial or Other, Competing Interest: None.

Submission 02-12-2015, Peer Review 03-12-2015,

Acceptance 19-12-2015, Published 23-12-2015.

Corresponding Author:

Dr. S. Ramesh,

Assistant Professor,

Department of ENT, RIMS, Srikakulam,

Andhra Pradesh.

E-mail: rameshseepana@rediffmail.com

DOI:10.14260/jemds/2015/2529 and unfavorable shape of the tube and too much laryngeal activity contributed to complications of prolonged intubation.Temporary functional symptoms are frequent after short-term intubation for anesthesia. Several patients complain of a minor sore throat and post intubation hoarseness frequently occurs.

In the majority common site of chronic changes in children is in the subglottic region. Persistent changes in the posterior glottis are not so well documented, but occur frequently in both adults (Bogdasarian and Olson, 1980). ${ }^{2}$ and children (Cohen 1981).

\section{Pathogenesis}

It is not feasible to leave a big anesthetic tube in the larynx without changes occurring. When pressure from the firm walls of the tube exceeds capillary pressure in the mucosa of the larynx, mucosal ischemia causes pain, swelling, and redness within the first few hours (Gaynor and Greenberg, 1985). ${ }^{3}$ Capillary perfusion pressure is the critical concern in mucosal injury - ischemic necrosis gives rise to epithelial damage and ulceration, the basic lesions from which complications occur (Weymuller, 1988). ${ }^{4}$ Confluent ulceration progresses to deep stromal necrosis and perichondritis after approximately 96 hours. If the endotracheal tube is removed at the point of minor epithelial injury, it heals by primary re-epithelialization.

Widespread ulcerative lesions heal by secondary intention with granulation formation. New collagen production in cases with wide or deep changes, which will lead to fibrous tissue and firm contracted scar tissue formation. This is the main basis for the development of chronic intubation changes, counting both subglottic and posterior glottic stenosis.

An endotracheal tube at all times lies in and exerts pressure on the posterior larynx, so there are three major areas of possible damage (Lindholm, 1969; Weymuller, 1988):

1. The medial surface and the vocal process of the the arytenoid cartilage.

2. The posterior commissure of vocal cord, which lies in the interarytenoid region.

3. The subglottic region, especially the anterior surface of the posterior lamina of the cricoid cartilage. 
A study was contemplated to evaluate these changes based on the duration of intubation in these patients, so that an early conversion from translaryngeal intubation can be recommended for prevention of the laryngeal sequelae after prolonged intubation.

\section{AIM OF THE STUDY}

The aim of study is to assess the changes in the larynx and trachea in post intubated patients.

\section{MATERIALS AND METHODS}

Thirty patients admitted to intensive care units in Government General Hospital, Kakinada, between September 2011 and August 2013 who underwent endotracheal intubation for more than seven days recovered and presenting with change of voice, noisy breathing, painful swallowing, etc. The study includes patients with road traffic accidents, non-corrosive poisoning, head injury, seizures, cerebral malaria and respiratory paralysis due to neurological diseases.

\section{SAMPLING METHOD}

\section{(a) Inclusion Criteria}

1. Age 15 to 65 years.

2. The patients admitted to ICUs who underwent endotracheal intubation for more than seven days, recovered and presenting with change of voice, noisy breathing, painful swallowing, etc.

\section{(b) Exclusion Criteria}

1. Patients with history of laryngeal disease.

2. Patients with trauma to the neck and airway.

3. Burns patients.

4. Patients who refused endoscopic examination.

\section{METHOD OF DATA COLLECTION}

The patients after history, clinical examination, complete ENT examination and appropriate investigations are scheduled for a rigid videolaryngoscopic examination and/or fibreoptic laryngotracheoscopic examination with a flexible bronchoscope. The findings are recorded and the patient is followed up at the end of one month and two months.

\section{OBSERVATION AND RESULTS}

This study conducted in the ENT Department is based on cases with changes in larynx and trachea following prolonged intubation in Intensive Care Units of Government General Hospital, Kakinada, during a period of about two years (September 2011 to August 2013).

In our series, we studied 30 patients with laryngeal and tracheal changes following prolonged intubation who are evaluated with rigid videolaryngoscopy and fibreoptic laryngo-tracheoscopy using a flexible bronchoscope.

\begin{tabular}{|c|c|c|}
\hline Sl. No. & SEX & No. of Cases \\
\hline 1 & Male & 18 \\
\hline 2 & Female & 12 \\
\hline \multicolumn{3}{|c|}{ Table I: Sex distribution of cases } \\
\hline
\end{tabular}

In this study, $60 \%$ of patients are male and $40 \%$ are female.

\begin{tabular}{|c|c|c|c|c|}
\hline $\begin{array}{c}\text { Sl. } \\
\text { No. }\end{array}$ & $\begin{array}{c}\text { Age In } \\
\text { Yrs }\end{array}$ & $\begin{array}{c}\text { No. of } \\
\text { Patients }\end{array}$ & $\begin{array}{c}\text { Total } \\
\text { Patients }\end{array}$ & Percentage \\
\hline 1 & $20-30$ & 7 & 30 & 23.33 \\
\hline 2 & $31-40$ & 7 & 30 & 23.33 \\
\hline 3 & $41-50$ & 11 & 30 & 36.67 \\
\hline 4 & $>50$ & 5 & 30 & 16.67 \\
\hline \multicolumn{5}{|c|}{ Table II: Age disribution of cases } \\
\hline
\end{tabular}

In our study, $36.67 \%$ belonged to age group of $41-50$ years, $23.33 \%$ belonged to $20-30$ years and $31-40$ years and $16.67 \%$ belonged to $>50$ years age group.

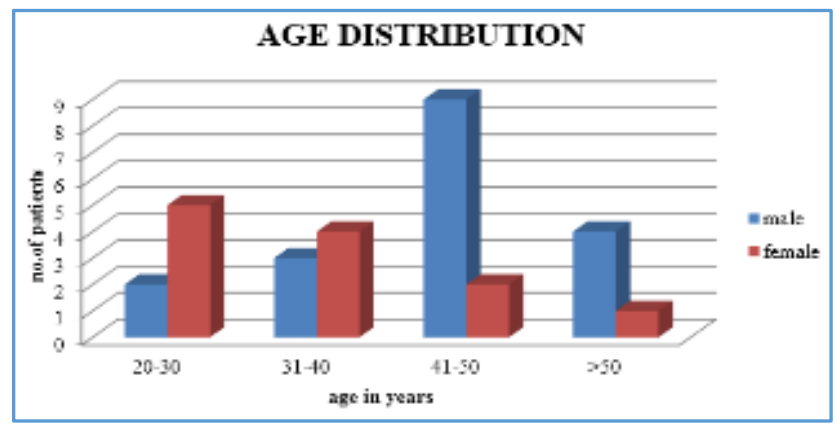

Fig. 1

\begin{tabular}{|c|c|c|}
\hline Sl. No. & Duration & No. of Patients \\
\hline 1 & $10-15$ days & 14 \\
\hline 2 & $16-20$ days & 12 \\
\hline 3 & $21-25$ days & 4 \\
\hline \multicolumn{3}{|c|}{$\begin{array}{c}\text { Table III: Distribution of duration of } \\
\text { intubation among patients }\end{array}$} \\
\hline
\end{tabular}

In our study 14 patients underwent 10-15 days of intubation, 12 patients underwent 16-20 days of intubation and 4 patients underwent 21-25 days of intubation.

\section{DISTRIBUTION OF DURATION OF INTUBATION AMONG PATIENTS}

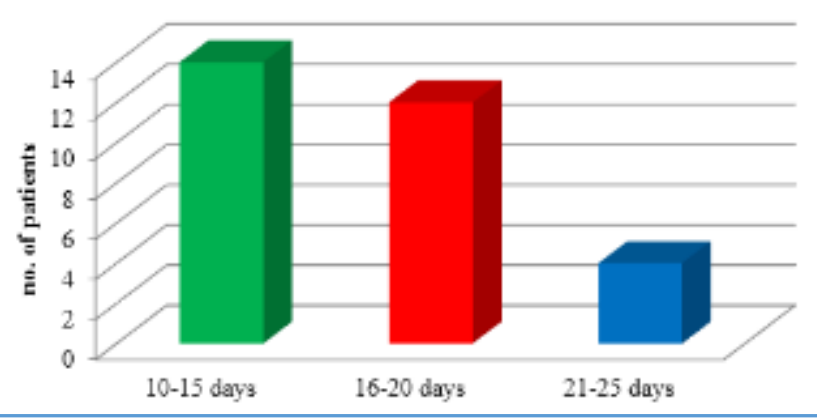

Fig. 2

\begin{tabular}{|c|c|c|c|}
\hline Sl. No. & Changes & Male & Female \\
\hline 1 & Larynx only & 12 & 8 \\
\hline 2 & Larynx and Trachea & 6 & 4 \\
\hline 3 & Trachea Only & 0 & 0 \\
\hline \multicolumn{3}{|c|}{ Table IV: Sex distribution of changes } \\
\hline
\end{tabular}

In our study 20 patients $(66.67 \%)$ had lesions only in larynx and 10 patients (33.33\%) had lesions in both larynx and trachea.

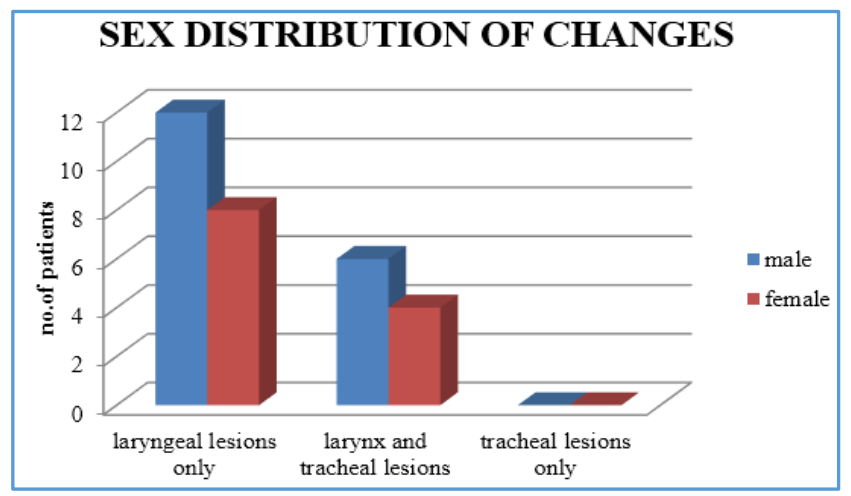

Fig. 3 


\begin{tabular}{|c|c|c|c|}
\hline Sl. No. & Lesion & Male & Female \\
\hline 1 & Epiglottis Ulcer & 2 & 1 \\
\hline 2 & Vocal Cord Granulomas & 3 & 2 \\
\hline 3 & Vocal Cord Ulcer & 0 & 2 \\
\hline 4 & Vocal Cord Scar & 2 & 1 \\
\hline 5 & Vocal Cord Edema & 0 & 1 \\
\hline 6 & Web Formation & 3 & 0 \\
\hline 7 & Arytenoid Subluxation & 2 & 1 \\
\hline 8 & Arytenoid Granulation & 1 & 1 \\
\hline 9 & Interarytenoid Adhesion & 3 & 1 \\
\hline 10 & Vocal Cord Palsy & 2 & 0 \\
\hline 11 & Subglottic Stenosis & 0 & 2 \\
\hline \multicolumn{2}{|c|}{ Table V: Sex distribution of laryngeal changes }
\end{tabular}

In our study, epiglottis ulcer was seen in 2 males and 1 female. Vocal cord granulomas were seen in 3 males and 2 females. Vocal cord ulcer was seen in 2 females. Vocal cord scar was seen in 2 males and 1 female. Vocal cord edema was seen in 1 female. Web formation was seen in 3 males. Arytenoid subluxation was seen in 2 males and 1 female. Arytenoid granulomas were seen in 1 male and 1 female. Interarytenoid adhesions were seen in 3 males and 1 female. Vocal cord palsy was seen in 2 males. Subglottic stenosis was seen in 2 females.

\section{SEX DISTRIBUTION OF LARYNGEAL CHANGES}

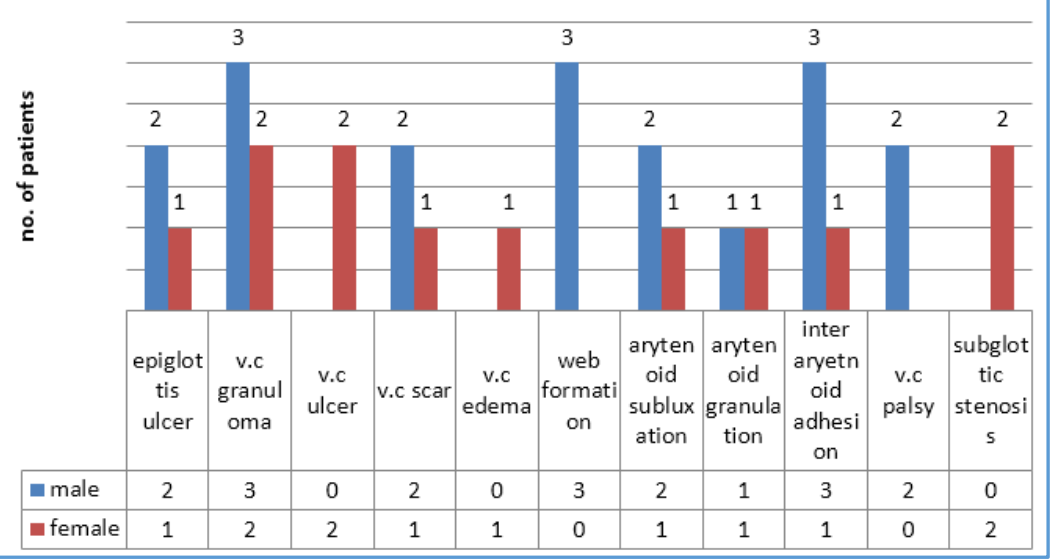

Fig. 4

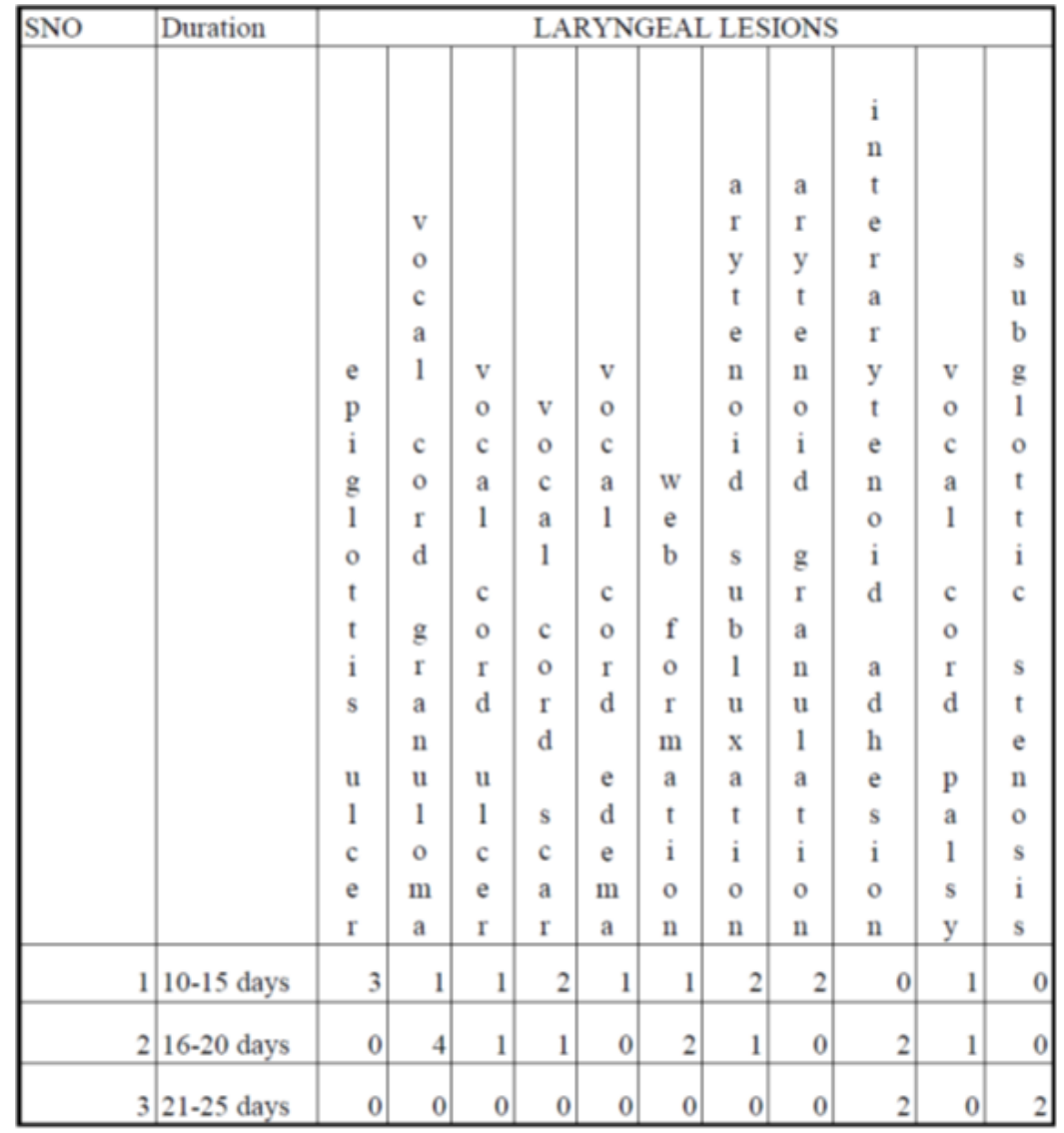

Table VI: Laryngeal changes in relation to duration of intubation 
In our study, among the patients who underwent 10-15 days intubation, 3 had epiglottis ulcer, vocal cord scar, arytenoid subluxation and arytenoid granulation are seen in 2 patients each. Vocal cord granulomas, vocal cord ulcer, vocal cord edema, web formation, vocal cord palsy are seen in 1 patient each. Among the patients who underwent 16-20 days intubation, 4 developed vocal cord granulomas. Web formation and interarytenoid adhesions are seen in 2 patients each and vocal cord ulcer, vocal cord scar, arytenoid subluxations are seen in 1 patient each. Two patients had interarytenoid adhesions and 2 had subglottic stenosis in those who underwent 21-25 days intubation.

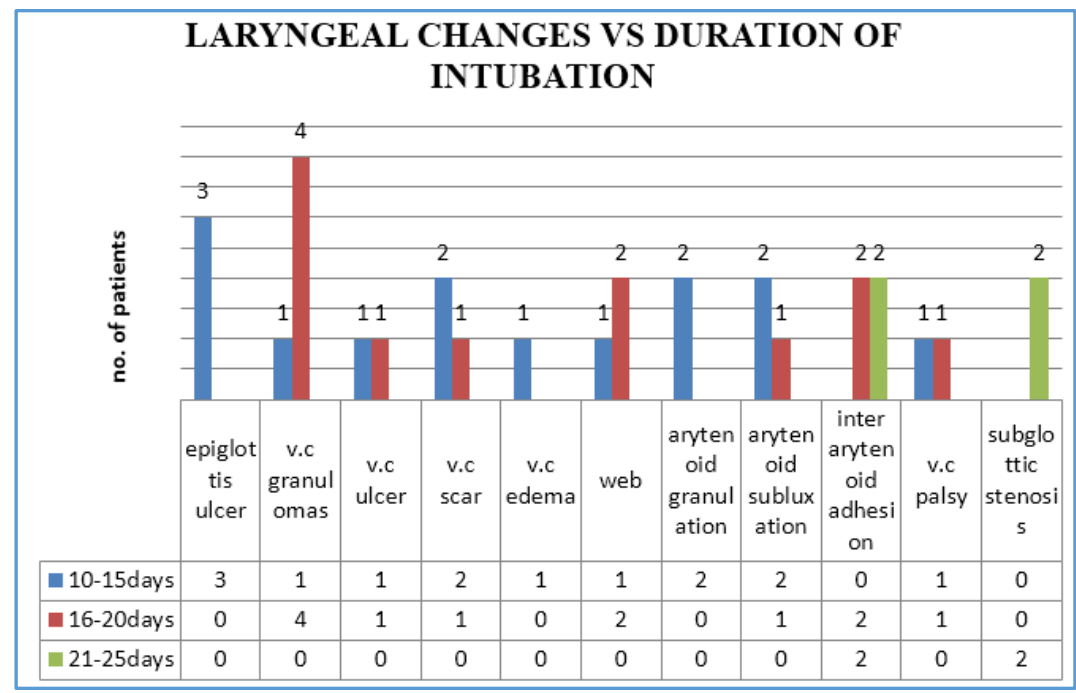

Fig. 5

\section{Patients with Changes in Trachea}

In our study of 30 patients, 10 patients had lesions in trachea along with lesions in larynx and 20 patients had lesions only in larynx.

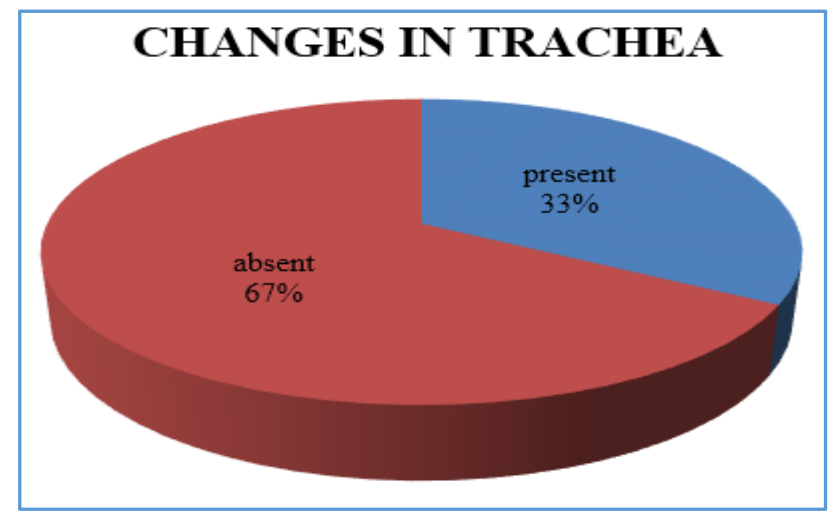

Fig. 6

\section{Sex Distribution of Changes in Trachea}

In our study of 30 patients, 10 had lesions in trachea; among them 4 males and 2 females had mucosal ulceration; 2 males and 2 females had mucosal edema; 12 males and 8 females had no tracheal changes.

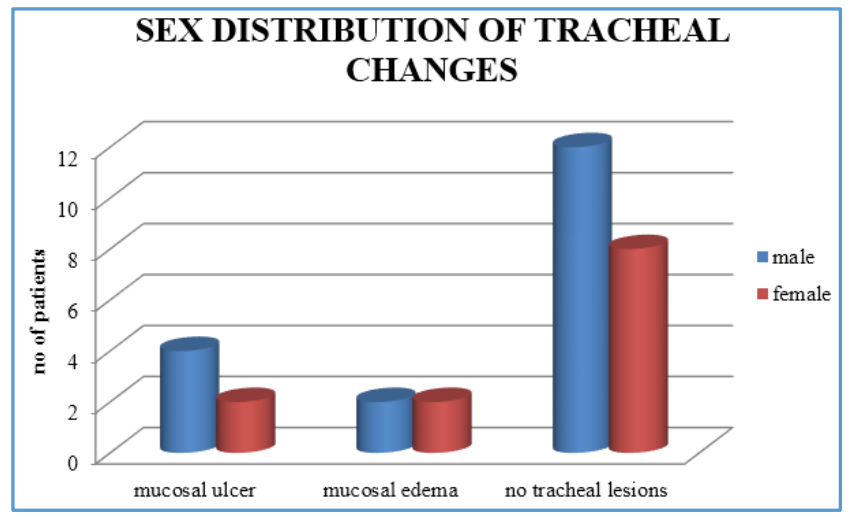

Fig. 7

\section{DISCUSSION}

Quite a large number of patients admitted in intensive care unit now-a-days require prolonged tracheal intubation for various reasons like assisted ventilation, protection of airway and tracheal bronchial toilet. Advances in medical treatment have led to an increase in the number of patients requiring intensive care and airway support. Along with this increase has grown the recognition that significant short and long-term morbidity may be associated with the use of artificial airways. Despite significant improvements in the biocompatibility of materials used in translaryngeal tubes and efforts to decrease the trauma associated with long-term intubation, laryngeal and tracheal lesions continue to be problematic in patients requiring prolonged airway support.

The endotracheal tube lies in the posterior portion of the larynx, hence the structures vulnerable to injuries are

1. Mucous membrane and mucoperichondrium covering the medial surface of arytenoid cartilages and their vocal processes.

2. Cricoarytenoid joints and adjoining parts of cricoid cartilage below.

3. Posterior glottic/interarytenoid regions.

4. Supraglottic structures, i.e. false vocal cords may become edematous (Reversible).

5. Tracheal injuries are uncommon with the advent of high volume/low pressure cuffs.

6. Over inflation of cuff of endotracheal tube may cause mucosal injury and ciliary loss in trachea.

7. Subglottic stenosis.

Blood circulation in the mucosa and mucoperichondrium can be interrupted when the pressure from the endotracheal tube exceeds capillary pressure. This may cause edema/hyperemia/ ulceration of mucosa/necrosis, ultimately leading on to erosion of perichondrium and cartilage.

Lindholm (1969) reported that prolonged intubation causes injuries to the larynx and trachea. His study established that the size and unfavourable shape of the tube and too much laryngeal activity contributed to complications. 
Whited RE. (1984). ${ }^{5}$ conducted a prospective study of laryngotracheal squeals in long term intubation in a series of 200 patients having 2-24 days intubation. In this study, he observed that group with 11-24 days intubation there is increased incidence as well as severity of post intubation complications.

GL. Colice, T. A. Stukel, B. Dain (1989). ${ }^{6}$ conducted a study on laryngeal complications of prolonged intubation. In this study, 82 patients who experienced Translaryngeal Intubation (TLI) for more than four days were prospectively evaluated for laryngeal complications. At the time of extubation, direct laryngoscopy was performed in these patients and laryngeal damage evaluated. A typical pattern of laryngeal damage was seen consisting of mucosal ulcerations along the posterior medial aspects of both vocal cords and varying degrees of laryngeal edema in 77 patients (94 percent).

Benjamin B. (1993). ${ }^{7}$ described prolonged intubation injuries of the larynx by endoscopic evaluation. In this paper significant, severe and lasting trauma of the larynx has been classified on the basis of the known factors in pathogenesis and observations made at endoscopy. This classification has required introduction of new descriptive terminology like "Tongues of Granulation tissue," "Ulcerated troughs," "Healed Furrows," and "Healed fibrous nodule."

Santos et al. (1994). 8 in their study noted that 79 patients who were examined laryngoscopically after prolonged endotracheal intubation $76 \%$ had ulcerations and $44 \%$ had granulomas. Majority of which are formed 4 weeks after intubation and reported that associated risk factors include duration of intubation, size of the tube and presence of nasogastric tube.

Thomas R., Kumar E.V., Kameswaran M., Shamim A., al Ghamdi S., Mummigatty A.P., Okafor B.C. (1995).${ }^{9}$ studied post intubation laryngeal sequelae in 12 bed multidisciplinary ICU for a period of 1 year. One hundred and fifty consecutive patients requiring intubation for more than 24 hours for various indications were studied. Evaluation of the larynx and trachea was done using a fibreoptic bronchoscope prior to elective extubation. One-hundred and thirty-one (87.6 percent) patients had visible laryngeal pathology in the immediate post-extubation period. Thirteen ( 8.6 percent) had long term sequelae. A high incidence of long term sequelae was noted in patients with seizures (25 percent) followed by patients with head injury (19 percent).

V. Rangachari, I. Sundararajan, V. Sumathi, K. Krishna Kumar. ${ }^{10}$ (2006) conducted a prospective study on laryngeal sequelae following prolonged intubation in South Indian population. About 51 patients were included in the study. Laryngeal abnormalities were seen in 41 patients on the day of extubation. At the end of third week after extubation, only 10 patients had abnormal laryngeal findings. They have concluded that laryngeal injury post extubation is directly related to the duration of intubation.

In our series, we studied 30 patients with laryngeal and tracheal changes following prolonged intubation who are evaluated with rigid videolaryngoscopy and fibrotic laryngotracheoscopy using a flexible bronchoscope.

In our study $60 \%$ of patients are male and $40 \%$ are female, probably owing to the fact that majority of the cases in our study were involved in RTA in which males are frequently involved.

In our study $36.67 \%$ belonged to age group of $41-50$ years, $23.33 \%$ belonged to $20-30$ years and $31-40$ years and $16.67 \%$ belonged to $>50$ years age group, mean age being 41 years.

In our study $14(46.67 \%)$ patients underwent $10-15$ days of intubation, $12(40 \%)$ patients underwent 16-20 days of intubation and $4(10 \%)$ patients underwent 21-25 days of intubation.
In our Study 20 patients (66.67\%) had lesions only in larynx and 10 patients (33.33\%) had lesions in both larynx and trachea. All the patients had lesions in the larynx and only $1 / 3$ rd of the patients had lesions in the trachea may be due to low volume high pressure cuffs in the trachea and unyielding walls of the tube exerting constant pressure on the vocal cords, arytenoids and subglottic region.

In our study epiglottis ulcer was seen in 2 males and 1 female $(10 \%)$. Vocal cord granulomas were seen in 3 males and 2 females. Vocal cord ulcer was seen in 2 females. Vocal cord scar was seen in 2 malse and 1 female. Vocal cord edema was seen in 1 female. Web formation was seen in 3 males. Arytenoid subluxation was seen in 2 males and 1 female. Arytenoid granulomas were seen in 1 male and 1 female. Interarytenoid adhesions were seen in 3 males and 1 female. Vocal cord palsy was seen in 2 males. Subglottic stenosis was seen in 2 females.

Above data shows 5 patients had vocal cord granulomas, which is the most frequent lesion encountered; 4 patients had interarytenoid adhesion which is the next common lesion followed by vocal cord scarring, web formation, arytenoid subluxation and epiglottic ulceration in 3 patients each. Subglottic stenosis, vocal cord palsy and vocal cord ulcer are seen in 2 patients each.

In our study among the patients who underwent 10-15 days intubation, 3 had epiglottis ulcer. Vocal cord scar, arytenoid subluxation and arytenoid granulation are seen in 2 patients each. Vocal cord granulomas, vocal cord ulcer, vocal cord edema, web formation, vocal cord palsy are seen in 1 patient each. Among the patients who underwent 16-20 days intubation, 4 developed vocal cord granulomas. Web formation and interarytenoid adhesions are seen in 2 patients each and vocal cord ulcer, vocal cord scar, arytenoid subluxations are seen in 1 patient each. Two patients had interarytenoid adhesions and 2 had subglottic stenosis in those who underwent 21-25 days intubation.

In our study duration of intubation ranged from 10 to 23 days and majority of the lesions are permanent sequelae post extubation following prolonged intubation.

This is in accordance with study conducted by Whited R. E. A prospective study of laryngotracheal sequelae in longterm intubation, which showed the increased incidence as well as the severity of post-intubation complications in patients with 11-24 days intubation.

In our study of 30 patients, 10 patients had lesions in trachea along with lesions in larynx and 20 patients had lesions only in larynx. Among them 4 males and 2 females had mucosal ulceration, 2 males and 2 females had mucosal edema.

Ulceration of trachea noted on the anterior wall of trachea, which probably occurred due to impingement of distal end of tube over the anterior wall of trachea. This may be due to movement or displacement of the endotracheal tube during the period of intubation. Mucosal edema may be due to constant pressure of the cuff over the tracheal mucosa. These could have been prevented by regular cuff pressure monitoring and prevention of movement of the patient by adequate sedation proper handling of the tube by ICU personnel.

\section{CONCLUSION}

In our study, 20 patients $(66.67 \%)$ had lesions only in larynx and 10 patients $(33.33 \%)$ had lesions in both larynx and trachea.

In our study, 5 patients had vocal cord granulomas which is the most frequent lesion encountered, 4 patients had interarytenoid adhesion which is the next common lesion followed by vocal cord scarring, web formation, arytenoid subluxation and epiglottic ulceration in 3 patients each. 
Subglottic stenosis, vocal cord palsy and vocal cord ulcer are seen in 2 patients each.

In our study, 10 patients had lesions in trachea along with lesions in larynx. Among them 4 males and 2 females had mucosal ulceration, 2 males and 2 females had mucosal edema. Meticulous intubation, proper sedation of intubated patients, early endoscopic evaluation and early intervention with tracheostomy will reduce post intubatory changes in larynx and trachea, thereby providing better care to the patients.

\section{REFERENCES}

1. Lindholm CE. Prolonged endotracheal intubation. A clinical investigation with special reference to its consequences for the larynx and trachea and to its place an alternative to intubation through a tracheostomy. Acta Anaesthesiol Scand 1969;33:1-131.

2. Bogdasarian RS, Olson NR. Posterior glottic stenosis. Otolaryngology and Head and Neck Surgery. 1980;88:76572.

3. Gaynor EB, Greenberg SB. Untoward sequelae of prolonged intubation. Laryngoscope. 1985 Dec;95(12):1461-7.
4. Weymuller EA Jr. Laryngeal injury from prolonged endotracheal intubation. Laryngoscope. $1988 \mathrm{Aug}$;98(8 Pt 2 Suppl 45):1-15.

5. Whited RE. A prospective study of laryngotracheal sequelae in long-term intubation. Laryngoscope 1984;94:367-77.

6. Colice GL, Stukel TA, Dain B. Laryngeal complications of prolonged intubation. Chest. 1989 Oct;96(4):877-84.

7. Benjamin B. Prolonged intubation injuries of the larynx: Endoscopic diagnosis, classification and treatment. Annal Otol Rhinol Laryngol Suppl 1993;160:1-15.

8. Santos PM, Afrassiabi A, Weymuller EA. Risk factors associated with prolonged intubation and laryngeal injury. Otolaryngol Head Neck Surg. 1994;111:453-459.

9. Thomas R, Kumar EV, Kameswaran M, Shamim A, Ghamdii SA, Mummigatty AP, et al. Post intubation sequelae in an intensive care unit. J Laryngol Otol 1995; 109:313-6.

10. Rangachari V, Sundararajan I, Sumathi V, et al. Laryngeal sequelae following prolonged intubation: A prospective study. Indian J Crit Care Med July-Sept 2006 Vol 10 Issue 3. 